The Influence Of Art Education On Students' Academic Learning In Kuwait

GHADEER ALHADDAD, MED, Ed. D

\author{
KUWAIT UNIVERSITY \\ COLLEGE OF EDUCATION, CURRICULUM AND INSTRUCTION
}

2018 


\begin{abstract}
The current study designed to statistically describe teachers' perceptions by asking questions on arts education and analyze the data for possible relationships of these experiences and perceptions. To accomplish this goal, this study used a survey questionnaire to investigate the perceptions of art education teachers, regarding the importance of art viewing, art making, and visual art education for students' academic achievements.
\end{abstract}

Teachers had participated and answered the questionnaire. The analysis established positive relationship between students' achievement and visual art education. In general, the survey's results confirmed the hypothesis that visual arts education correlates with students' positive educational outcomes. After reviewing the literature in this area and receiving responses to the questionnaire, suggestions and recommendations for future research in art education curriculum will be offered.

Keywords: Art, Art Education, Visual Art Education, Art Appreciation. 


\title{
INTRODUCTION
}

\section{AND THE REVIEW OF THE LITERATURE}

"Every child is an artist. The problem is how to remain an artist once we grow up."

\author{
Pablo Picasso
}

Arts education has the influence and the power of its characteristic value and worth (Hayes, 2015). Arts and art education are important, helpful, and valuable to our schools, society, and life. Several studied have discussed the importance of art education and art viewing experiences in education. As Hayes stated in her recent study, "There is growing evidence of positive outcomes, international acclaim, and current and revised advocacy in support of arts education in school settings" (Hayes, p.93, 2015).

However, remark discussions by particular researchers and recognized studies stated that art education have slight effect on students positive outcomes. According to Epstein and Trimis, 2002, art appreciation experiences are minor component for children's education (Epstein and Trimis, 2002). Moreover, other researchers claimed that art and art education is an ignored subject. As Eckhoff (2008) stated, "art appreciation and art viewing experiences continue to be an overlooked component of

early arts experiences" (pp.270). As well as, other studied showed that studying the arts might expose positive impact on students' achievement, but not connection to skill development or to academic areas (Winner \& Cooper, 2000). 
In spite of this, there are great numbers of researchers and studies that provided and delivered the importance of art education on students' academic learning. Plus, there are some "current evidence, does show rich evidence of the value of visual arts education leading to further knowledge and achievement" (Hayes, 2015, pp.31), and other investigators and philosophers confirmed that students could express their thinking, which influences ways of knowing, motivate growth, and strengthen habits of mind (Eisner, 2002; Rostan, 2010; Hayes, 2015). According to Midgette, "arts education is raising its hand again" (Midgette, 2013).

Art education growing and flourishing again in the field of education. As indicated in Hayes research, “Arts Education Partnership (AEP) announcements (2013), arts initiatives go hand in hand with school improvement and student achievement, providing important advantages to student learning not seen in achievement through standardized tests" (Hayes, 2015, pp.2), and claimed "the arts are considered to be core academic subjects" (Hayes, 2015, pp.2). Besides, many arts education organization support-teaching activities associated with art experiences (NAEA 1994). Last but not least, a previous study by Zimmerman (1994) supported that "Visual arts education in the United States has undergone many changes in a positive direction" (pp.79).

Bring to a close, Elliot Eisner, a professor of art and education at the Stanford Graduate School of Education, and was one of the United States' leading academic minds, believed in the strong positive relationship between visual arts education and students' motivation, perceptions, and academic balance (1998). For instance, Knight (2010) argue that "visual arts lessons are best placed to provide fully students with such critique because they help students to develop a 'critical eye', an interpretive lens often 
used by artists to view, analyses and independently navigate and respond to contemporary society" (pp.236). To the point, understanding the importance of visual art and art education possibly will provide success and knowledge to students.

Indeed, arts education is important and essential to students. It provides knowledge, skills, and values to achieve advanced and progressive educational outcomes. A study by Eckhoff, A (2008) advised that, "the visual arts can be an important and rich domain of learning for young children" (pp.463). Truly today's students are experiencing arts and visual art culture everyday into their lives. Therefor, Arts are needed to enhance achievement, develop motivation in learning, and improve school culture (Hayes, 2015).

For example, Knight emphasized (2010) "It is a common acceptance that contemporary schoolchildren live in a world that is intensely visual and commercially motivated, where what is imagined and what is experienced intermingle. Because of this, contemporary education should encourage a child to make reference to, and connection with their 'out-of-school' life" (pp.236). In addition, Knight included, "the ability for a student to talk about art process from some level of shared knowledge base, no matter how rudimentary, provides an extra avenue of meaning” (pp.239). Further, Eckhoff recommended in her study, that art education becomes an important part of understanding the educational practices occurring within the students' classroom (Eckhoff, 2008). Furthermore, Eckhoff, Added, "art experiences for young children include activities designed to introduce children to works of art that are high quality and developmentally appropriate in both content and presentation.” (pp.463). 
To summarize, art education and visual arts give students opportunities to respond, critique, and questions the images they experienced in their modern society. As well as, develop critical thinking and interpretation skills. According to Fiske as stated in Hayes research, "the idea is that engagement in visual arts "provides unparalleled opportunities for learning that enables young people to reach for and attain higher levels of achievement" (Fiske, 1999, p. 15). Visual art education can absolutely and positively examine and analyze critical skills (Knight, 2010). It is important to understand arts education and visual arts. Hetland and Winner declared, "the arts must be justified in terms of what the arts can teach that no other subject can teach" $(2001$, p.3).

At the end, all components of the setting, teachers, students, artworks, and art materials come together to create effective learning experiences (Eckhoff, 2008). Moreover, Knight, (2010) suggested "School, and particularly art education, has a responsibility to educate students about culture, to expose them to its nature and award them with critical, analytical tools to negotiate it" (pp. 283).

In that content, this study examined art teachers' perceptions of the importance of visual arts and art education in schools, curriculums, and students' education. Besides explored, argued, and discussed the question, to what degree or extent do art educators observe, reflect or perceive that art education and visual arts education impact or contribute to positive educational outcomes in student success and achievement? For this purpose, this study provided a deeper level of understanding and interpreting visual art and art education. 


\section{SIGNIFICANCE OF THIS STUDY \\ AND STUDY DESCRIPTION}

The primary purpose of this study was to explore art education teacher's views and perceptions of the importance of visual arts and art education in schools. An additional purpose of this study was to highlight the importance of engagement art viewing and art making to emphasize the importance of visual arts curriculum. This study took place in Kuwait City during the academic year 2017-2018. On the base of the hypothesis that art education teachers are positive toward the importance of visual art and art education in students' education and learning.

\section{PROBLEM STATEMENT}

It is likely that there are multiple factors that contribute to this study:

First, In spite of the recommendations of art viewing and art appreciate experiences, the visual art education remains a minor component of young student's arts education. Second, Art educators suffer the lack of art education training, visual art knowledge, and art appreciation experience. Therefore, the null hypothesis for research question states that art educators do not perceive that visual arts contribute to positive educational outcomes in student achievement.

\section{RESEARCH QUESTIONS}

The following research question was addressed in this study: 
Null hypotheses $\mathrm{H} 0=$ Art educators do not observe or perceive that visual arts add or contributes to positive educational outcomes in student success and achievement. H1=Art educators do observe or perceive that visual arts add or contributes to positive educational outcomes in student success and achievement.

To what degree or extent do art educators observe or perceive that art education and visual arts education impact or contribute to positive educational outcomes in student success and achievement?

\section{DEFINITION OF TERMS}

For the purpose of this study, terms were defined as follows:

Arts Education - Skill based instruction in various art disciplines (New York statewide Local Capacity Building Coordinators, 2005).

Perception - For the purpose of this study, it is believed or opinion hold by many people and based on appearances (Cambridge dictionary).

Art - The expression or application of human creative skill and imagination, typically in a vision form such as painting or sculpture, producing work to be appreciated primary for their beauty or emotion power (Oxford dictionary).

Visual Arts - As defined by the National Art Education Association, a broad category of the arts that includes traditional fine arts, such as drawing, painting, printmaking, photography, and sculpture; media arts including film, graphic communications, 
animation, and emerging technologies; architectural, environmental, and industrial arts such as urban, interior, product, and landscape design; folk arts; and works of art such as ceramics, fibers, jewelry, works in wood, paper, and other materials, communication and design arts, and architecture and environmental arts ((NAEA, 2014).

Visual Culture - Is the aspect of culture expressed in visual images (Wikipedia). Another definition by Knight, visual culture is a contemporary and historical artworks produced by artists as well as the visual adverts, television, video, digital interfaces and the like of popular culture (Knight 2010).

\section{THE STUDY}

\section{METHOD AND DESIGN}

The current study designed to statistically describe art education teachers' perceptions by asking questions and opinions on visual arts and art education experiences and gather and analyze the data for possible relationships of these perceptions. To accomplish this goal, art teachers had participated and answered the survey questionnaire. "Survey studies are considered a field approach to collecting data and producing statistics from a defined population using a questionnaire" (Hayes, p.97, 2015).

The research design was a descriptive data analysis, and outcomes of the dependent variable, teacher perceptions, and independent variables, contextual experiences and practices were the resultant outcomes of the question survey. The 
questionnaire was then created, collected, and analyzed through Question Pro, online survey software.

\section{PARTICIPANTS}

The data for the current study were collected during the academic year of the 2017-2018. The questionnaire was completed online (Hayes, P.2015) and through SMS. Participation in the questionnaire was voluntary, and all subjects had the option to choose whether to complete and return the questionnaire. Time spent on the survey ranged from five minutes to fifteen minutes, averaged at ten minutes to complete the survey questionnaire. Information was provided with each survey questionnaire to explain the importance of the study, the purpose of the study, the amount of time that is needed to complete the questionnaire, a consent form, and contact information for the investigator and the research advisor. "Participants created the data and conclusions are drawn from results depending on individual responses averaged together within groups of the sample" (Hayes, p.97, 2015).

The questionnaire was distributed and collected by the researcher. The alpha is a standard 0.05. Sample of this study was Kuwait public schools. A sample of 67 participants were completed the survey with a margin of error 5\% and confidence level $95 \%$. The response rate for this study was $86.25 \%$.

\section{INSTRUMENT}


The instrument was meant to measure art education teachers' views and perceptions of the importance of art education and visual art education on student outcomes and achievement. Numerical values were assigned to possible responses of each statement with scores ranging from 0 and 1 (lowest), to 4 (highest). The instrument is intended to provide descriptive information to measure art education teachers' perceptions regarding the value of visual arts education.

The instrument used in this study was a survey designed to determine students and educators' perceptions of the importance of the independent variables (experiences, social contexts, and demographics) to predict the dependent variable (attitude) toward arts education (Hayes, 2015). The measurements were the survey questionnaire and the independent variable was the questions. This descriptive data was used to investigate and explore frequencies and percentages on the levels of agreement or disagreement. Nominal and ordinal scale scores were coded and entered into Question Pro software. Answers and feedback from the participants were measured through categories themes. And coding the answers by theme also considered. "The instrument was meant to measure and predict or explain respondents' perceptions and influences towards arts education" ((Hayes, 2015, pp.42).

The survey questionnaire was adapted and modified from both Kampouropouluo, M., Athanasiadis, I., Stefos, E., \& Rhodes, G. (2011) and from (Hayes, P. 2015) study, and was modified to be based on the issues that related to the art education curriculum as discussed in the introduction and literature review (Darling-Hammond, Chung, \& Frelow, 
2002) and based on the culture, tradition and religion in the state of Kuwait. The survey was pre-tested with a convenience sample of two participants and then a convenience sample of ten participants. This method is used to ensure that the survey questions were clearly understood and the participants are able to answer every question in the questionnaire, and the survey questions are measured what they were intended to measure (Harrell, 2007).

The survey is described in a following segment. The survey contained items asking for demographic and background information, questions on the importance of visual arts and art education in schools and curriculums, students' education. The questionnaire had ten questions, which concentrated and focused on several arts education issues. A self-administered questionnaire was used for this study. The mode of the questionnaire used in this study was the type that a respondent completes on his/her own on paper. Scale formation method using Likert scaling in the survey to measure participant's strength of positive or negative perception and attitude toward visual art and art education (Luehrman, 1999; Hayes, P. 2015). "For each statement or question, participants were asked to select a response from the following to allow investigation of the extent of agreement or disagreement: strongly agree, agree, not applicable (NA), disagree, and strongly disagree. A number value (0) NA to (4) was assigned to possible responses and allowed the investigator to sum up and obtain individuals' instrument scores" (Hayes, 2015).

\section{PROCEDURES}


In order to extract the research results, this study used a descriptive data analysis. The data were presented in a descriptive manner with frequency distributions and percentages. In this study, purposeful sampling used for represent participants who were proposed to be part of the sample (Hayes, P. 2015). Participants represented a subgroup of a larger population of public schools (Vogt \& Johnson, 2011). This study used Question Pro, online survey software, to gather and collect data. Survey questionnaires were sent by emails, SMS, and QR codes. All survey responses were automatically synced and analyzed in a customized survey dashboard.

Total size of population and the percentage of the returns surveys were reported. The demographic responses were categorized through descriptors and reported as percentages. Survey respondents were coded, and comparisons between responses also were reported. The data collected during the spring semester of the year 2017-2018 in Kuwait public schools. A total of $(n=67)$ art teachers were participated in this study.

\section{RESULTS AND FINDING}

The results of this study were gathered through online survey questionnaires that explore art teachers' views and perceptions of the importance of visual arts and art education in schools. The analysis showed that most art teachers are positive towards the importance of visual art and art education in students' education and confirmed the positive relationship between students' achievement and visual art education. In general, 
the survey's results confirmed the hypothesis that visual arts education correlates with students' positive educational outcomes.

When asked the first question in the survey, do you agree or disagree that, "For those with little drawing talent there is not much to be gained by taking an art education class". $53.85 \%$ of teachers who were participated in the survey "disagree" with the statement and were approved that students with little drawing talent there is much to be gained by taking an art class. As much as, $16.92 \%$ of the teachers who took part in this survey "strongly disagree" with the statement and were approved that students with little drawing talent there is much to be gained by taking an art class. In contrast, $21.54 \%$ of teachers who were participated in the survey "agree" that students with little drawing talent there is not much to be gained by taking an art class. As though, $6.15 \%$ of the teachers who took part in this survey "strongly agree" that students with little drawing talent there is not much to be gained by taking an art class. Just $1.54 \%$ of the participants stated that they "neither agree or disagree" that students with little drawing talent there is not much to be gained by taking an art class. In (table 1, chart 1), It appeared that the majority of the participants do believe that students with little drawing talent can find much to be gained by taking an art class.

Table 1:

\begin{tabular}{|c|c|c|c|}
\hline & Answer & Count & Percent \\
\hline & Strongly agree & 4 & $6.15 \%$ \\
\hline & Agree & 14 & $21.54 \%$ \\
\hline
\end{tabular}




\begin{tabular}{|l|r|r|}
\hline 3. Disagree & 35 & $53.85 \%$ \\
\hline 4. Strongly disagree & 11 & $16.92 \%$ \\
\hline 5. N/A & 1 & $1.54 \%$ \\
\hline Total & 65 & $100 \%$ \\
\hline
\end{tabular}

\section{Chart 1:}

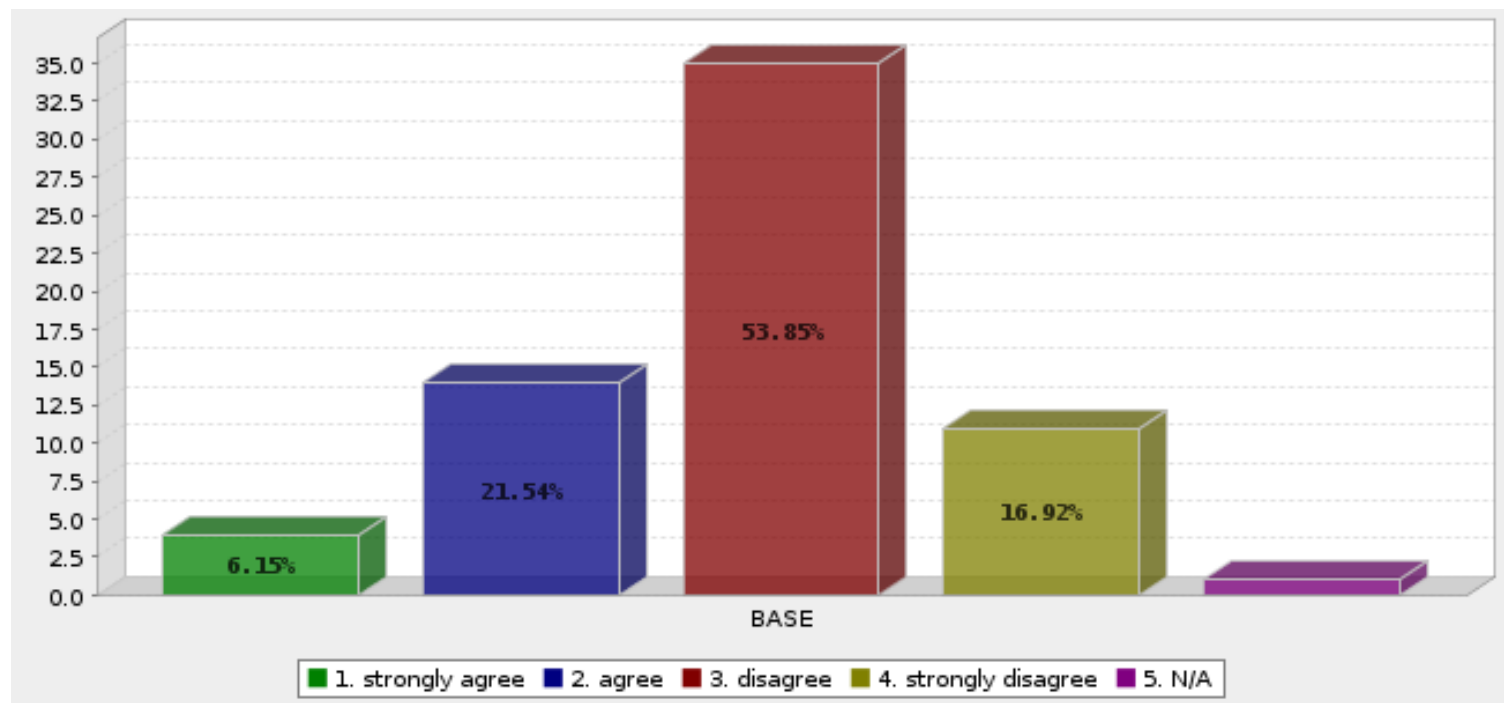

When asked the second question in the survey, "do you agree or disagree that art education teaches critical thinking skills". $43.55 \%$ of teachers who were participated in the survey "strongly agree" that art education teaches critical thinking skills. Equally, $43.55 \%$ of teachers who were participated in the survey "agree" that art education teaches critical thinking skills. Whereas, $8.06 \%$ of teachers who were participated in the survey "disagree" with the statement that art education teaches critical thinking skills. Only $1.61 \%$ of the teachers who took part in this survey "strongly disagree" with the statement that art education teaches critical thinking skills. Merely $3.23 \%$ of the participants stated 
that they "neither agree or disagree" that art education can teach students critical thinking skills. In (table 2, chart 2), provided that most of the participants believed that art education can teaches students critical thinking skills.

Table 2:

\begin{tabular}{|c|c|c|c|}
\hline & Answer & Count & Percent \\
\hline & Strongly Agree & 27 & $43.55 \%$ \\
\hline 2. & Agree & 27 & $43.55 \%$ \\
\hline & Disagree & 5 & $8.06 \%$ \\
\hline & Strongly Disagree & 1 & $1.61 \%$ \\
\hline & N/A & 2 & $3.23 \%$ \\
\hline & Total & 62 & $100 \%$ \\
\hline
\end{tabular}

Chart 2:

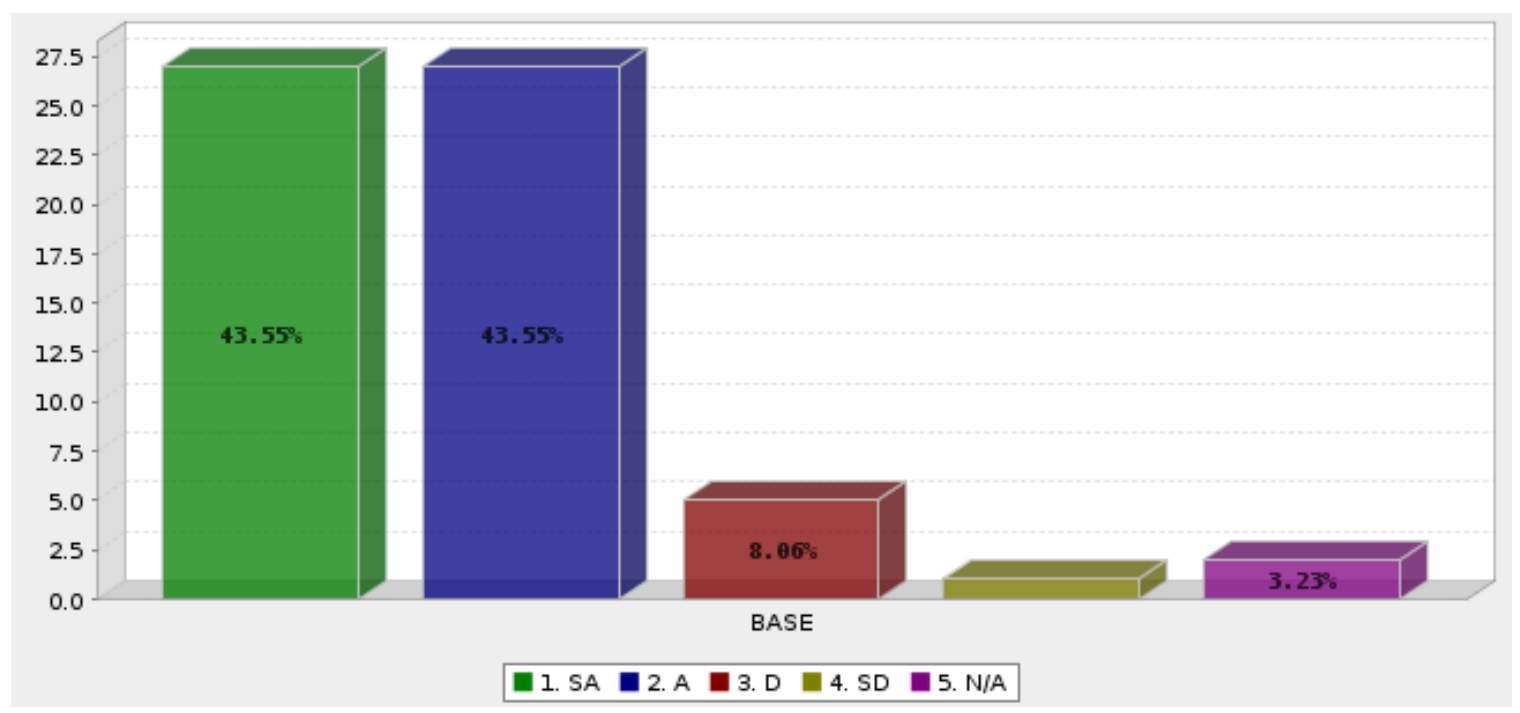


In question 3 teachers are asked do you agree or disagree that, "Visual art education is not an important part of school curriculum". $45.31 \%$ of teachers who were participated in the survey "disagree" with the statement that visual art education is not an important part of school curriculum. And $21.88 \%$ of the teachers who took part in this survey "strongly disagree" with the statement that visual art education is not an important part of school curriculum. In compare, $15.62 \%$ of teachers who were participated in the survey "agree" that visual art education is not an important part of school curriculum. And $7.81 \%$ of the teachers who took part in this survey "strongly agree" that visual art education is not an important part of school curriculum. Curiosity about $9.38 \%$ of the participants stated that they "neither agree or disagree" that visual art education is not an important part of school curriculum. Accordingly, as stated in (table 3, chart 3), the majority of the participants confirmed that visual art education is an important part of school curriculum.

Table 3:

\begin{tabular}{|r|r|r|}
\hline \multicolumn{1}{|c|}{ Answer } & Count & Percent \\
\hline 1. Strongly Agree & 5 & $7.81 \%$ \\
\hline 2. Agree & 10 & $15.62 \%$ \\
\hline 3. Disagree & 29 & $45.31 \%$ \\
\hline 4. Strongly Disagree & 14 & $21.88 \%$ \\
\hline 5. N/A & 6 & $9.38 \%$ \\
\hline Total & 64 & $100 \%$ \\
\hline
\end{tabular}


Chart 3:

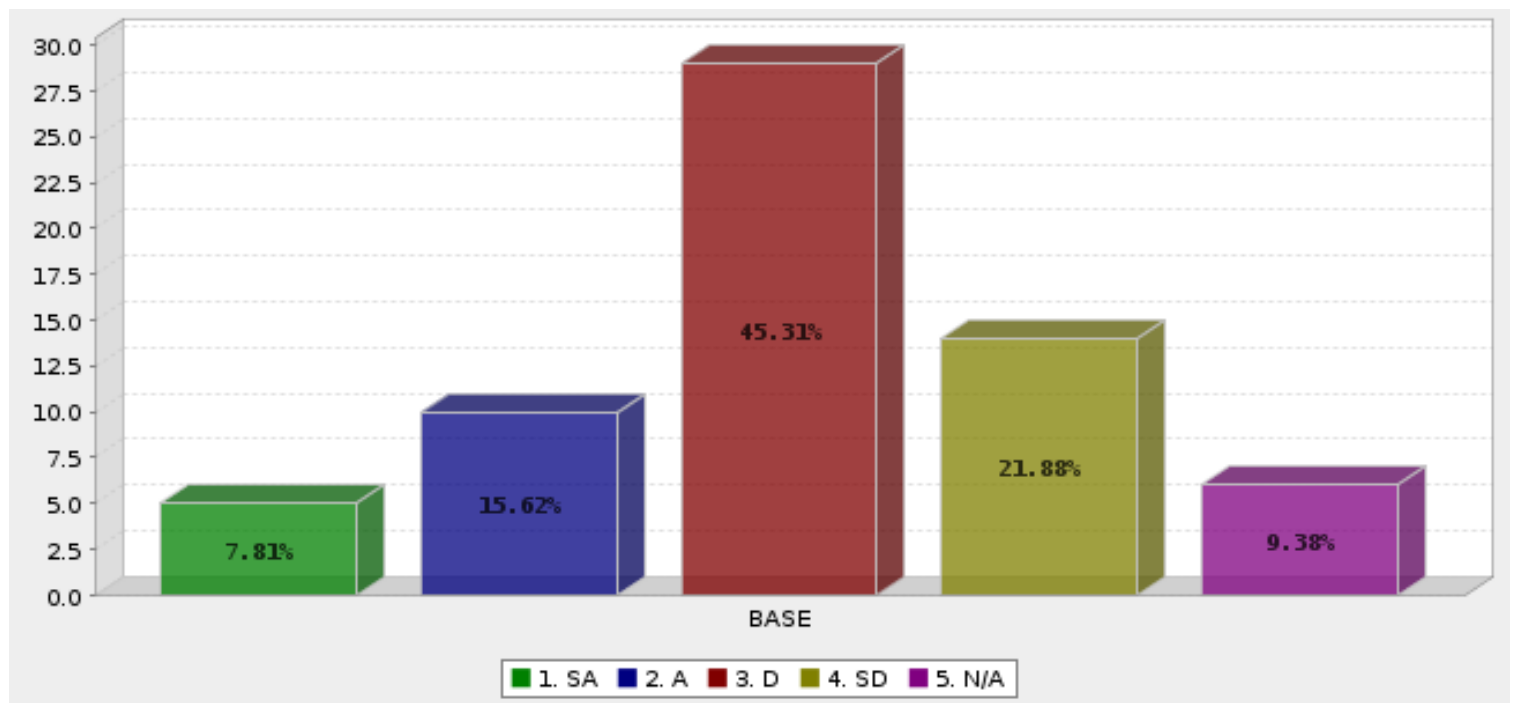

When raised the forth question do you agree or disagree that "Arts education offers important learning opportunities that are unavailable through other subjects". $58.73 \%$ of teachers who were contributed in the survey, "Agree" with the statement "Arts education offers important learning opportunities that are unavailable through other subjects". And $26.98 \%$ of the teachers who took part in this study "Strongly Agree" with the statement "Arts education offers important learning opportunities that are unavailable through other subjects". In compare, $9.52 \%$ of teachers who were participated in the survey "Disagree" with the statement "Arts education offers important learning opportunities that are unavailable through other subjects". Wonder, about $4.76 \%$ of the participants stated that they "neither agree or disagree" that "Arts education offers important learning opportunities that are unavailable through other subjects". Correspondingly, as stated in (table 4, chart 4), the majority of the participants approved that arts education offers important learning opportunities that are unavailable through other subjects. 
Table 4:

\begin{tabular}{|l|r|r|}
\hline \multicolumn{1}{|c|}{ Answer } & Count & Percent \\
\hline 1. Strongly Agree & 17 & $26.98 \%$ \\
\hline 2. Agree & 37 & $58.73 \%$ \\
\hline 3. Disagree & 6 & $9.52 \%$ \\
\hline 4. Strongly Disagree & 0 & $0.00 \%$ \\
\hline 5. N/A & 3 & $4.76 \%$ \\
\hline Total & 63 & $100 \%$ \\
\hline
\end{tabular}

Chart 4:

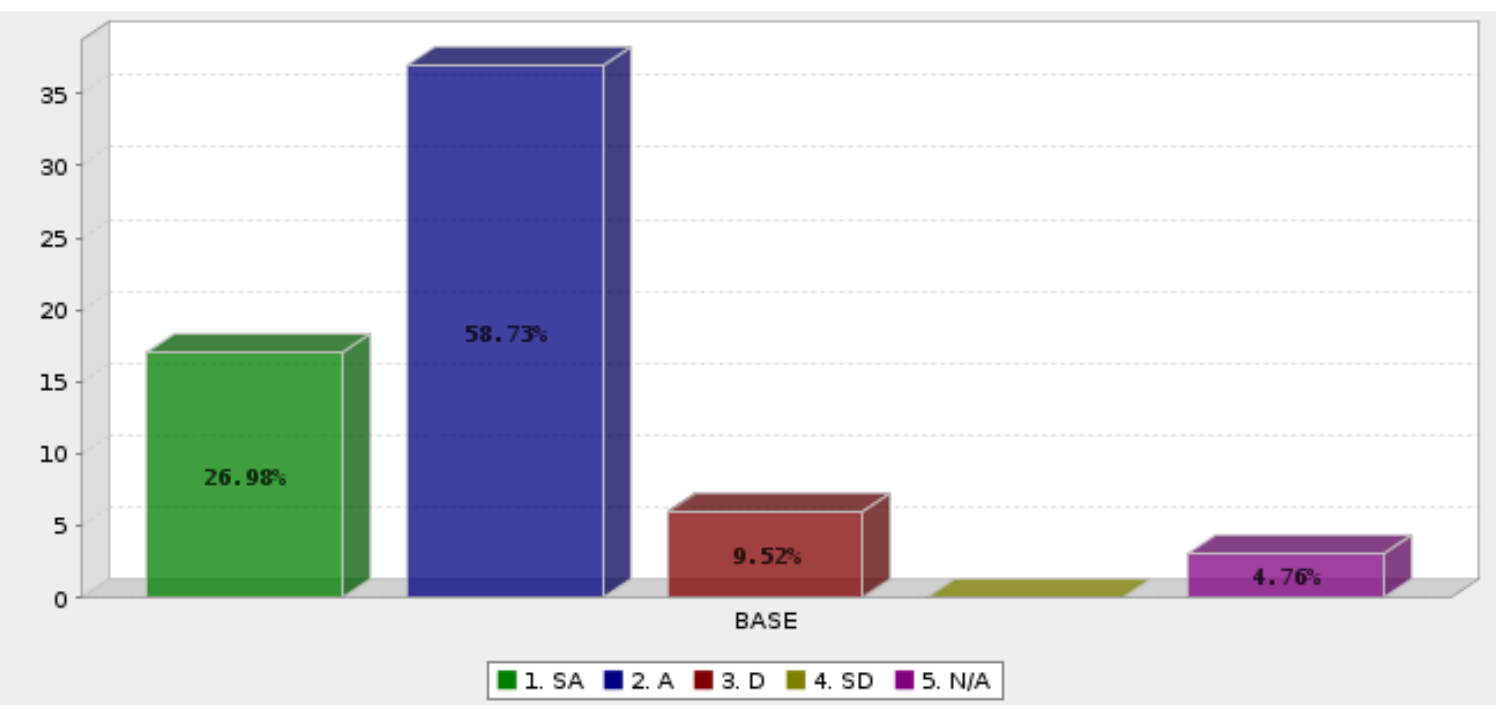

When brought up the fifth question do you agree or disagree that "Students should be given grades or assessment reports in art just as they are in other subjects". As show in 
table 5 and chart $5,58.73 \%$ of teachers who were part of the survey, "Agree" with the statement "Students should be given grades or assessment reports in art just as they are in other subjects". Plus $22.22 \%$ of the teachers who done this study "Strongly Agree" with the statement "Students should be given grades or assessment reports in art just as they are in other subjects". Whereas, $14.29 \%$ of teachers who were partaken in the survey "Disagree" with the statement "Students should be given grades or assessment reports in art just as they are in other subjects". Besides $4.76 \%$ of the teachers who participated in this study "Strongly Disagree" with the statement "Students should be given grades or assessment reports in art just as they are in other subjects". Correspondingly, the majority of the participants supported that Students should be given grades or assessment reports in art just as they are in other subjects.

Table 5:

\begin{tabular}{|c|c|c|c|}
\hline & Answer & Count & Percent \\
\hline & Strongly Agree & 14 & $22.22 \%$ \\
\hline 2. & Agree & 37 & $58.73 \%$ \\
\hline & Disagree & 9 & $14.29 \%$ \\
\hline & Strongly Disagree & 3 & $4.76 \%$ \\
\hline & $\mathrm{N} / \mathrm{A}$ & 0 & $0.00 \%$ \\
\hline & Total & 63 & $100 \%$ \\
\hline
\end{tabular}

Chart 5: 


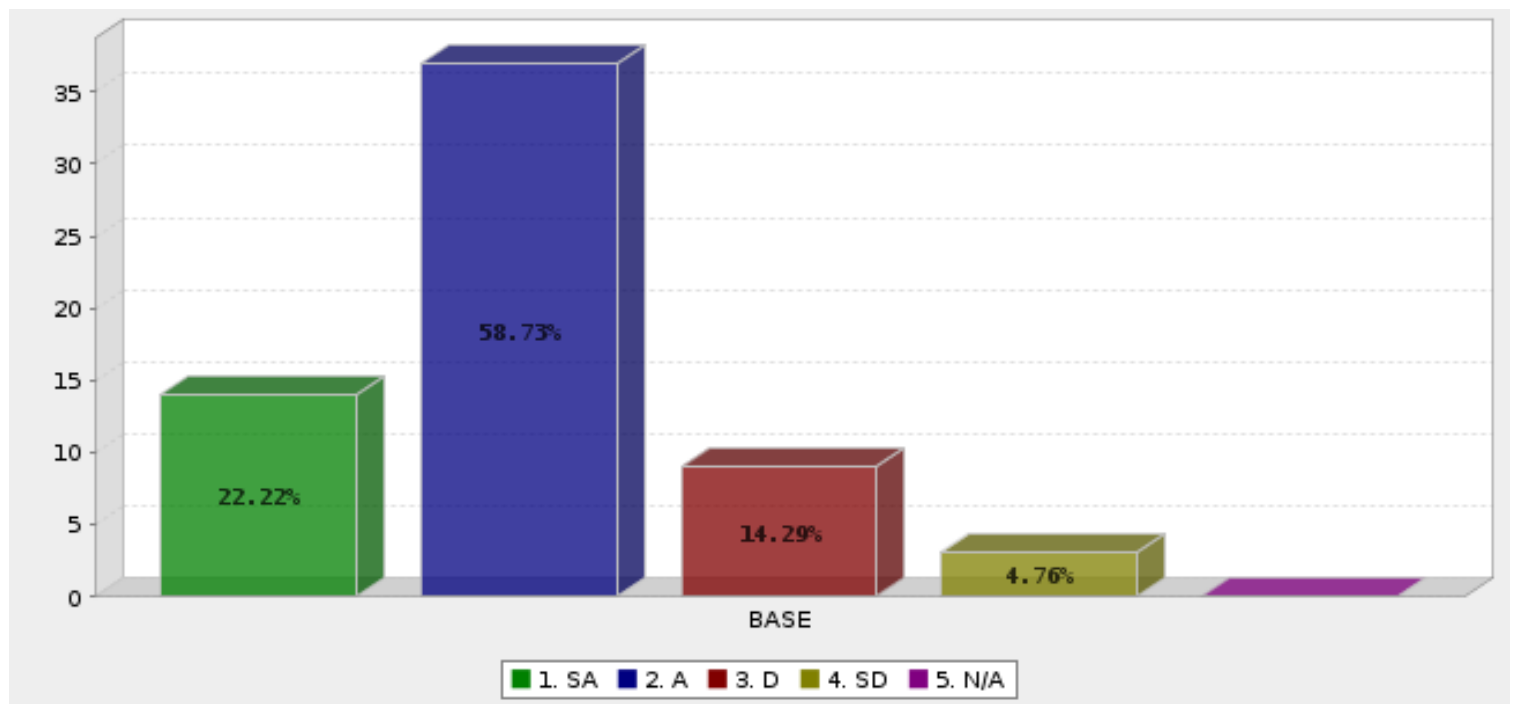

In question 6 teachers are asked do you agree or disagree that "The primary purpose for art education in the school is to provide entertaining breaks from other more serious subjects". $46.03 \%$ of teachers who were part of the survey, "Agree" with the statement "The primary purpose for art education in the school is to provide entertaining breaks from other more serious subjects". In addition to $14.29 \%$ of the teachers who did this study "Strongly Agree" with the statement "The primary purpose for art education in the school is to provide entertaining breaks from other more serious subjects". Whereas, $30.16 \%$ of teachers who were participated in the survey "Disagree" with the statement "The primary purpose for art education in the school is to provide entertaining breaks from other more serious subjects". Moreover $6.35 \%$ of the teachers who joined the study "Strongly Disagree" with the statement "The primary purpose for art education in the school is to provide entertaining breaks from other more serious subjects". Afterward, about $3.17 \%$ of the participants stated that they "neither agree or disagree" that "The primary purpose for art education in the school is to provide entertaining breaks from other more serious subjects". Correspondingly, as in (table 6, chart 6), the majority of the 
participants supported that the primary purpose for art education in the school is to provide entertaining breaks from other more serious subjects.

Table 6:

\begin{tabular}{|r|r|r|}
\hline \multicolumn{1}{|c|}{ Answer } & Count & Percent \\
\hline 1. Strongly Agree & 9 & $14.29 \%$ \\
\hline 2. Agree & 29 & $46.03 \%$ \\
\hline 3. Disagree & 19 & $30.16 \%$ \\
\hline 4. Strongly Disagree & 4 & $6.35 \%$ \\
\hline 5. N/A & 2 & $3.17 \%$ \\
\hline Total & 63 & $100 \%$ \\
\hline
\end{tabular}

Chart 6:

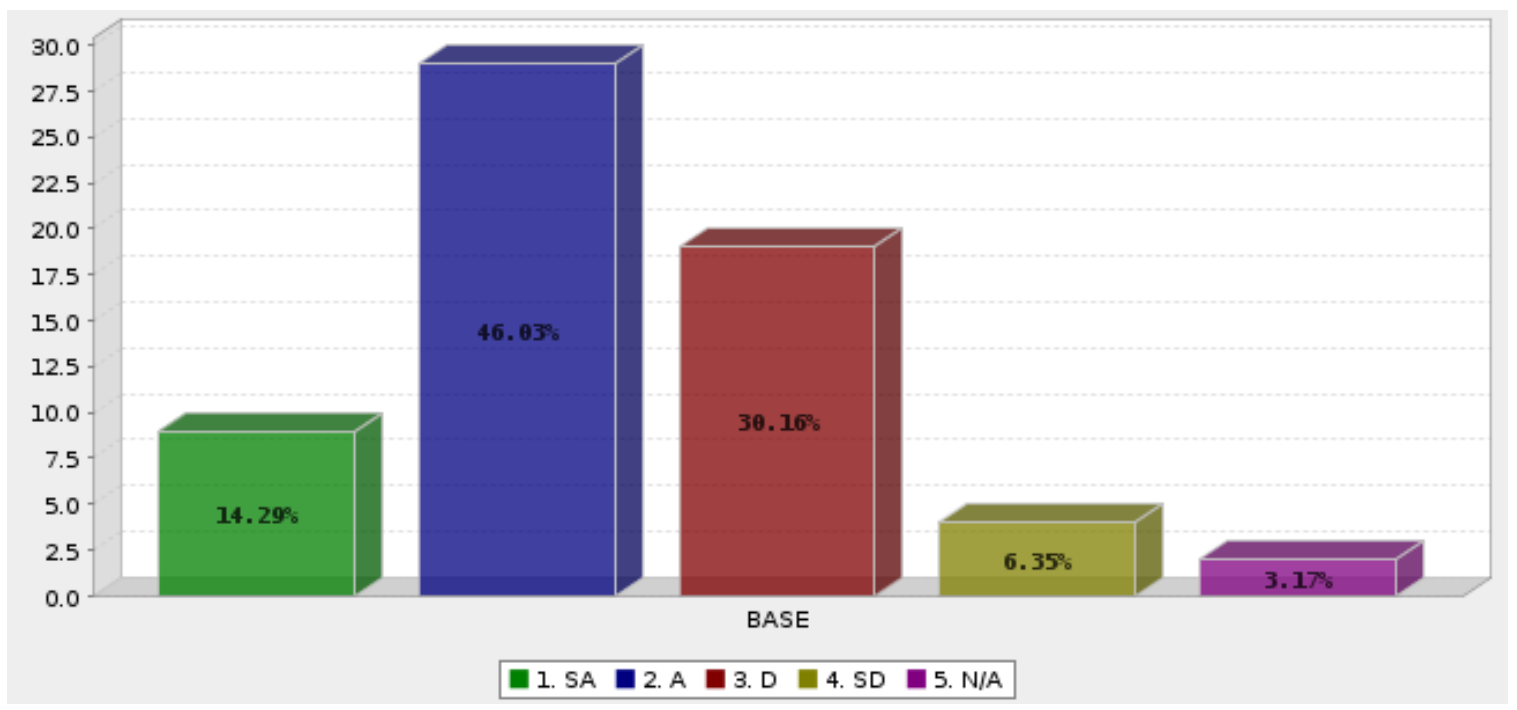


According to (table 7, chart 7), when asked the seventh question do you agree or disagree that "Teaching art is less demanding (less serious) than teaching other subjects". $45.16 \%$ of teachers who were part of the study, "Agree" with the statement "Teaching art is less demanding (less serious) than teaching other subjects". Furthermore, $6.45 \%$ of the teachers who did this study "Strongly Agree" with the statement "Teaching art is less demanding (less serious) than teaching other subjects". However, $41.94 \%$ of teachers who were participated in the survey "Disagree" with the statement "Teaching art is less demanding (less serious) than teaching other subjects". Besides, $4.84 \%$ of the teachers who joined the study "Strongly Disagree" with the statement "Teaching art is less demanding (less serious) than teaching other subjects". Barely, about $1.61 \%$ of the participants stated that they "neither agree or disagree" that "Teaching art is less demanding (less serious) than teaching other subjects". Correspondingly, the majority of the participants supported that Teaching art is less demanding (less serious) than teaching other subjects.

\section{Table 7:}

\begin{tabular}{|l|r|r|}
\hline \multicolumn{1}{|c|}{ Answer } & Count & Percent \\
\hline 1. Strongly Agree & 4 & $6.45 \%$ \\
\hline 2. Agree & 28 & $45.16 \%$ \\
\hline 3. Disagree & 26 & $41.94 \%$ \\
\hline 4. Strongly Disagree & 3 & $4.84 \%$ \\
\hline 5. N/A & 1 & $1.61 \%$ \\
\hline
\end{tabular}


Chart 7:

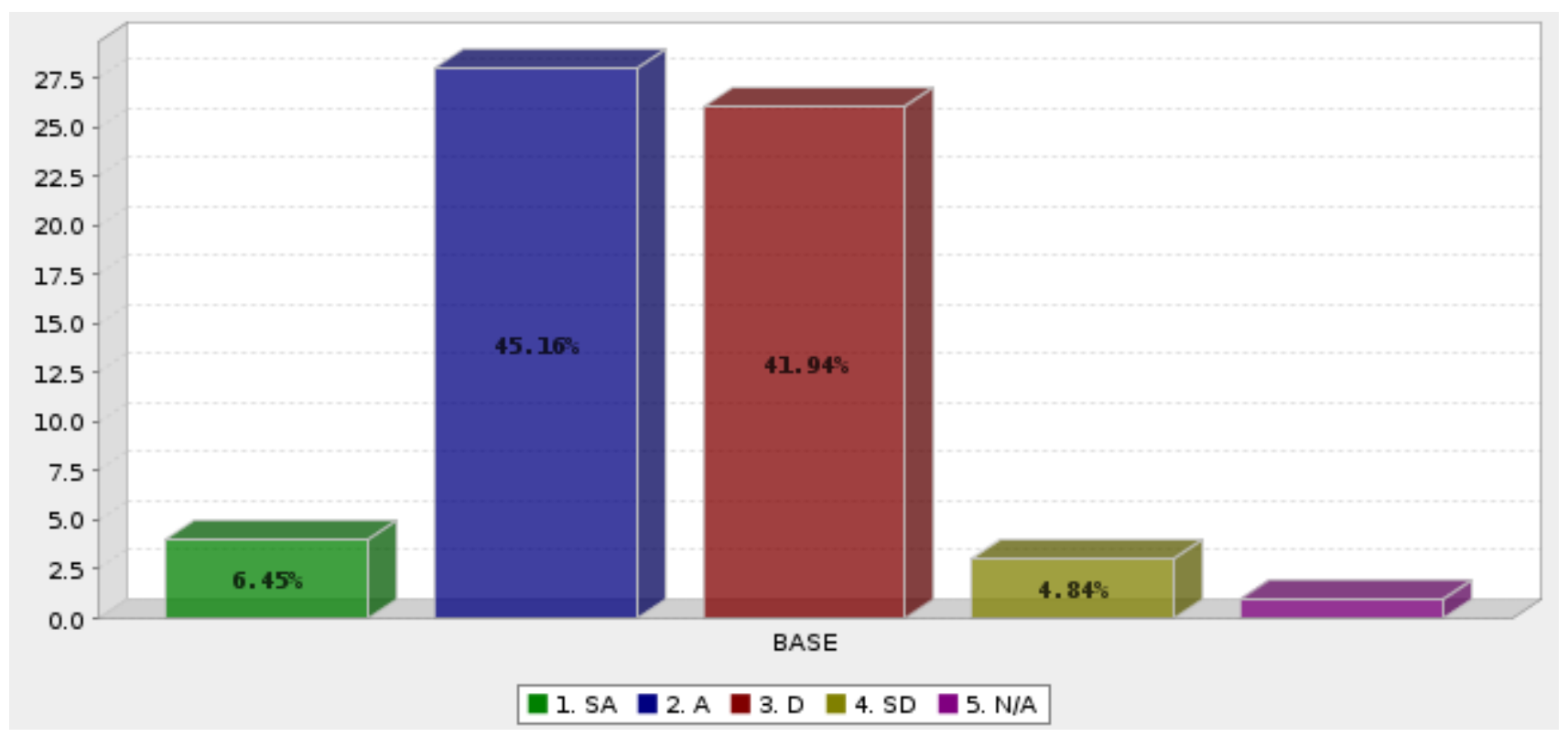

In question 8 teachers are asked do you agree or disagree that "Art classes should be one of the first eliminated from the curriculum if a cut is necessary". $54.69 \%$ of teachers who were part of this study, "Disagree" with the statement "Art classes should be one of the first eliminated from the curriculum if a cut is necessary". Additionally, $21.88 \%$ of the teachers who did this study, "Strongly Disagree" with the statement "Art classes should be one of the first eliminated from the curriculum if a cut is necessary". Though, $18.75 \%$ of teachers who were participated in this survey "Agree" with the statement "Art classes should be one of the first eliminated from the curriculum if a cut is necessary". Besides, $1.56 \%$ of the teachers who joined the study "Strongly Agree" with the statement "Art classes should be one of the first eliminated from the curriculum if a 
cut is necessary". Just, about $3.12 \%$ of the participants stated that they "neither agree or disagree" that "Art classes should be one of the first eliminated from the curriculum if a cut is necessary". In that order, in (table 8, chart 8), the majority of the participants supported that Art classes should not be one of the first eliminated from the curriculum if a cut is necessary.

Table 8:

\begin{tabular}{|c|c|c|}
\hline Answer & Count & Percent \\
\hline 1. Strongly Agree & 1 & $1.56 \%$ \\
\hline 2. Agree & 12 & $18.75 \%$ \\
\hline 3. Disagree & 35 & $54.69 \%$ \\
\hline 4. Strongly Disagree & 14 & $21.88 \%$ \\
\hline 5. N/A & 2 & $3.12 \%$ \\
\hline Total & 64 & $100 \%$ \\
\hline
\end{tabular}

Chart 8: 


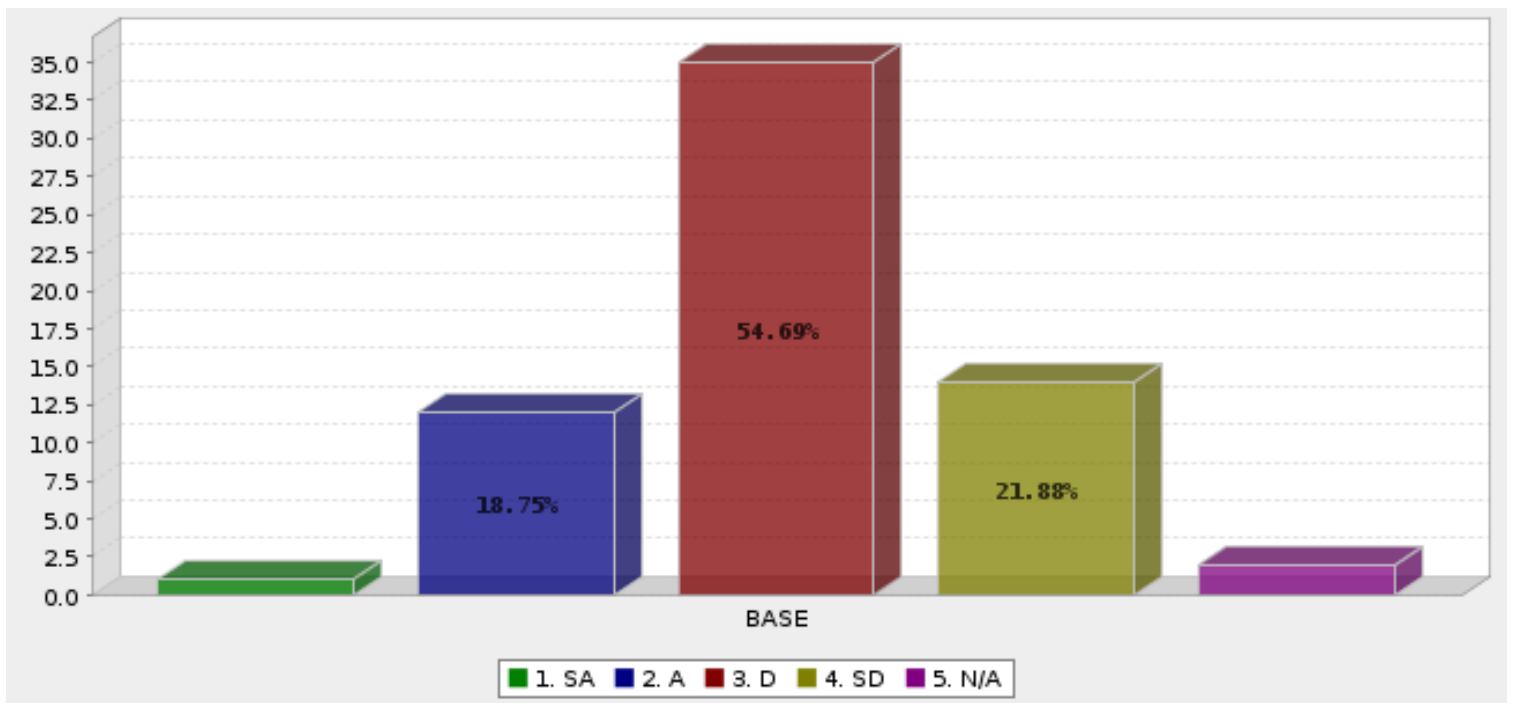

Question 9 asked, do you agree or disagree that "Visual art is an important subject with specific content worth knowing”. Table 9 and chart 9 show $64.06 \%$ of teachers who were part of this study, "Agree" with the statement "Visual art is an important subject with specific content worth knowing”. Additionally, $26.56 \%$ of the teachers who did this study, "Strongly Agree" with the statement "Visual art is an important subject with specific content worth knowing". However, $7.81 \%$ of teachers who were participated in this survey "Disagree" with the statement "Visual art is an important subject with specific content worth knowing". Barely, about $1.56 \%$ of the participants stated that they "neither agree or disagree" that "Visual art is an important subject with specific content worth knowing". In that order, the majority of the participants supported that Visual art is an important subject with specific content worth knowing.

\section{Table 9:}

\begin{tabular}{|l|l|l|}
\hline Answer & Count & Percent \\
\hline
\end{tabular}




\begin{tabular}{|l|r|r|}
\hline 1. Strongly Agree & 17 & $26.56 \%$ \\
\hline 2. Agree & 41 & $64.06 \%$ \\
\hline 3. Disagree & 5 & $7.81 \%$ \\
\hline 4. Strongly Disagree & 0 & $0.00 \%$ \\
\hline 5. N/A & 1 & $1.56 \%$ \\
\hline Total & 64 & $100 \%$ \\
\hline
\end{tabular}

Chart 9:

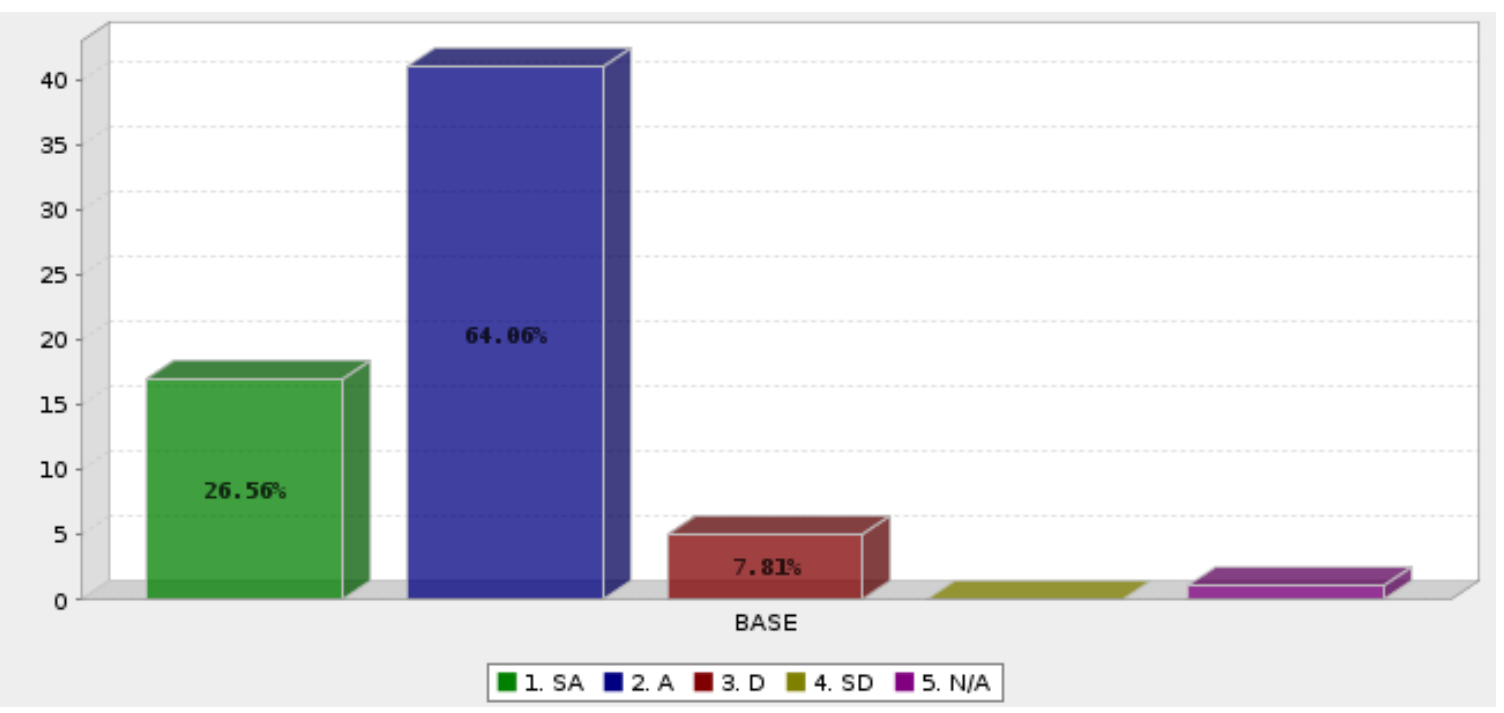

When asked the last question do you agree or disagree that "A strong arts program is a sign of a strong overall educational program in school". In table 10, chart 10, $46.88 \%$ of teachers who were part of this study, "Agree" with the statement "A strong arts program is a sign of a strong overall educational program in school”. Similarly, $46.88 \%$ of the teachers who did this study, "Strongly Agree" with the statement "A strong arts program is a sign of a strong overall educational program in school". On the other hand, 
$6.25 \%$ of teachers who were participated in this survey "Disagree" with the statement "A strong arts program is a sign of a strong overall educational program in school”. Seldom of the participants stated that they "neither agree or disagree" that "A strong arts program is a sign of a strong overall educational program in school". In that order, quite clearly the majority of the participants supported that a strong arts program is a sign of a strong overall educational program in school.

Table 10:

\begin{tabular}{|c|c|c|c|}
\hline & Answer & Count & Percent \\
\hline & Strongly Agree & 30 & $46.88 \%$ \\
\hline 2. & Agree & 30 & $46.88 \%$ \\
\hline & Strongly Disagree & 0 & $0.00 \%$ \\
\hline & Disagree & 4 & $6.25 \%$ \\
\hline & N/A & 0 & $0.00 \%$ \\
\hline & Total & 64 & $100 \%$ \\
\hline
\end{tabular}

Chart 10: 


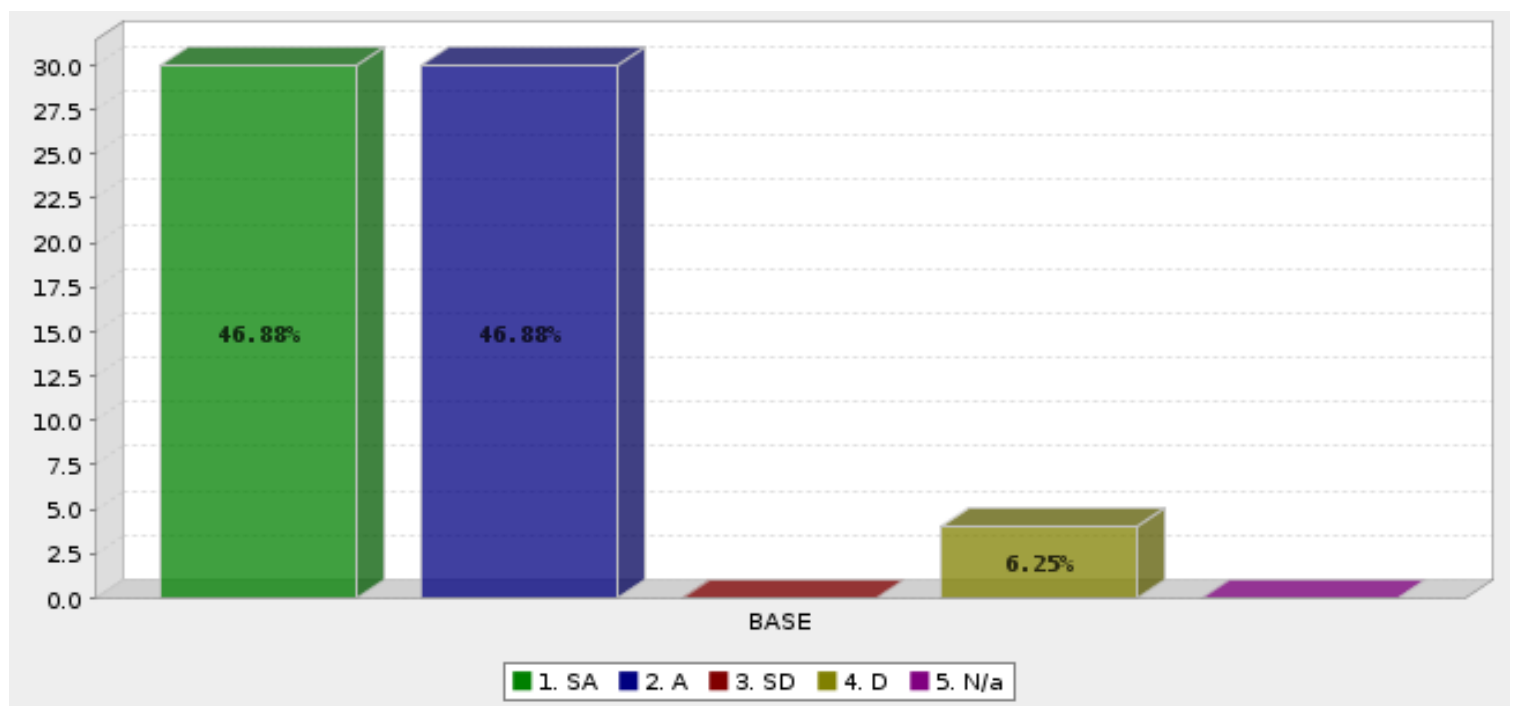

\section{DISCUSSION OF THE RESULTS}

The purpose of the study was to explore and describe art education teachers' perceptions and attitude toward visual arts and art education in public schools. This study presented the analysis of survey questionnaire that was created, collected, and analyzed through Question Pro, online survey software, which allowed for differentiation criteria to emerge as well as for their classification in groups, depending on the teachers' common answers to the questionnaire. The data are used here to answer the following research questions, which have guided this study; to what degree or extent do art educators observe, reflect or perceive that art education and visual arts education impact or contribute to positive educational outcomes in student success and achievement?

Perceptions and opinions of participating art teachers were measured through frequencies and percentages. Results were demonstrated from the analyses and shows high frequency of positive responses to support arts education ranging from $80 \%-100 \%$ 
positive agreement on 10 questions. As supported by the results of this study, it appeared that above $50.00 \%$ of the students who took part in the survey believed that students with little drawing talent can find much to be gained by taking an art class. Undeniably above $80.00 \%$ of the students who took part in the survey believed that art education can teaches students critical thinking skills. Indeed above $50.00 \%$ of the students who took part in the survey confirmed that visual art education is an important part of school curriculum.

Undoubtedly above $80.00 \%$ of the students who took part in the survey believed that arts education offers important learning opportunities that are unavailable through other subjects. Further about $80.95 \%$ of the students who took part in the survey believed that students should be given grades or assessment reports in art just as they are in other subjects. Furthermore $60.32 \%$ of the students who took part in the survey believed that the primary purpose for art education in the school is to provide entertaining breaks from other more serious subjects. Provided that the majority of the participants supported that teaching art is less demanding (less serious) than teaching other subjects. Presently, It is interesting that more than $50.00 \%$ of the participants supported that Art classes should not be one of the first eliminated from the curriculum if a cut is necessary.

Certainly, $90.62 \%$ of the participants supported that visual art is an important subject with specific content worth knowing. Undoubtedly above $85 \%$ of the participants who took part in this study believed that a strong arts program is a sign of a strong overall educational program in school. Given that fact, finding and results show that educators do 
perceive and reflect that the art education and visual arts education impact and contribute to positive educational outcomes in student success and achievement.

\section{CONCLUSIONS}

Following on the previous discussion, certain conclusions were made. As the primary purpose of this study was to explore the perceptions of the importance of visual arts and art education in schools, the analysis showcased that the majority of the participants agreed that visual art is an important part of the school curriculum.

In summary, the survey's results confirmed the hypothesis of a positive attitude of art teachers toward the importance of visual art and art education in students' education. This study concluded that art education and visual art education are important in students' education (Eckhoff, 2008; Kolbe, 2005) and are essential to expanded students' knowledge, skills, and achievement (Hayes, 2015). According to Burton, as stated in Hayes study, "arts education has a history in public schools and theory that contributes to strong learning environments" (Burton et al., 2000). In conclusion, these findings confirmed that these educators remark and perceive the importance and value of arts education in schools and curriculums.

\section{LIMITATIONS, RECOMMENDATIONS, AND SUGGESTIONS FOR FURTHER RESEARC}


Based upon study findings and conclusions, the following suggestions and future research recommendations are made. Future investigators would be advised to explore both the effectiveness and the importance of visual art and art education. Inferences from this study suggest undertaking research on the understanding of the relationship between art education and early childhood education in current classroom curriculum and instructional practices. Research and inquiry is needed to use different data methods such as observation, interviews.

Further, continued studies are desirable and needed to encourage interaction and links between students in their same interest fields locally and internationally where they can share thoughts and feedback. Furthermore, this study recommended encouraging the relationship between art education and early childhood educations. Lastly, this study focused only on art teachers' perceptions of the importance of visual arts and art education in schools and curriculums.

\section{REFERENCES}

1. LCB Coordinators. (2005, Spring). Arts in education definitions. Retrieved from http://www.earts.org/usr/AIE_Definitions.pdf

2. Arts Education Partnership. (2013, 2014). State of the states 2014: Arts education state policy summary. Retrieved from http://www.aep-arts.org

3. Arts Education Partnership. (2013). Common core and the arts. Retrieved from http://www.aep-arts.org/resources-2/common-core-and-the-arts

4. Eckhoff, A. (2008). The Importance of Art Viewing Experiences in Early Childhood Visual Arts: The Exploration of a Master Art Teacher's Strategies for 
Meaningful Early Arts Experiences. Early Childhood Education Journal, 35:463472.

5. Burton, J. M., Horowitz, R., \& Abeles, H. (2000). Learning in and through the arts: The question of transfer. Studies in Art Education, 41, 228-257.

6. Eisner, E. W. (1998). Does experience in the arts boost academic achievement? Arts Education Policy Review, 100, 32-40. http://dx.doi.org/10/2307/1320236

7. Epstein, A. S., \& Trimis, E. (2002). Supporting young artists: The development of the visual arts in young children. Yipsilanti, MI: High/Scope Press.

8. Fiske, E. B. (Ed.). (1999). Champions of change: The impact of the arts on learning.Retrieved from ERIC database. (ED435581)

9. Hetland, L., Winner, E., Veenema, S., \& Sheridan, K. M. (2013). Studio thinking: The real benefits of arts education. Retrieved from ERIC database. (ED4977825)

10. Kampouropouluo, M., Athanasiadis, I., Stefos, E., \& Rhodes, G. (2011). Students' views on the using of new technologies in art education: An interdisciplinary approach to higher education. Review of European Studies, 3(1), 60-70.

11. Kampouropouluo, M., Athanasiadis, I., Stefos, E., \& Rhodes, G. (2011). Teaching art using technology: the views of high school students in Greece. Review of European studies, 3(2), 98-109.

12. Kolbe, U. (2005). It's not a bird yet: The drama of drawing. Australia: Peppinot Press.

13. Knight, L (2010). Why a Child Needs a Critical Eye, and Why the Art Classroom is Central in Developing it. JADE 29.3/NSEAD/Blackwell Publishing Ltd. Pp. 236-243.

14. Luehrman, M. (1999). The art experiences of Missouri public school principals and their attitude toward art education (Doctoral dissertation). Received from author Luehrman, 11/2014.

15. Midgette, A. (2013). After years of crouching, arts ed is raising it's hand again. Retrieved from http://www.washingtonpost.com/blogs/

16. National Art Education Association. (1992, 1994, 2014). National coalition for core art standards. Retrieved from http://www.arteducators.org/research/nccas

17. National Art Education Association. (1994). The national visual arts 
standards. Reston, VA: National Art Education Association.

18. Harrell, L. A. (2007). Beginning art teachers in Florida: Perceptions of their preparation to teach art. The Florida State University. Retrieved October 18. 2012

19. Hayes, Patricia A. (2015), "High Quality Visual Arts Education K-8, The Student, The Principal, and The Teacher". Education Dissertations. 4.

20. Rogoff, I. (1998) Studying visual culture, in N. Mirzoeff [Ed.] The Visual Culture Reader, 2nd edn. Abingdon: Routledge, pp. 24-36

21. Rostan, S. M. (2010). Studio learning: Motivation, competence, and the development of young art students' talent and creativity. Creativity Research Journal, 22, 261- 271. http://dx.doi.org/1080/10400419.2010.503533

22. Zimmerman, E (1994). Current Research and Practice about Pre-Service Visual Art Specialist Teacher Education. National Art Education Association. Studies in Art Education, Vol. 35, No. 2 (Winter, 1994), pp. 79-89.

23. Vogt, P. \& Johnson, B. (2011). Dictionary of statistics \& methodology: A nontechnical guide for the social sciences. Thousand Oaks, CA: Sage Publications.

24. Darling-Hammond, L., Chung, R., \& Frelow, F. (2002). Variation in teacher preparation: how well do different pathways prepare teachers to teach? Journal of Teacher Education, 53(4), 286-302. 